\title{
O vivido da pessoa com sequelas da COVID-19 e a percepção do corpo segundo a ótica merleaupontyana
}

The experience of the person with COVID-19 sequelae and the perception of the body according to Merleauponty's perspective

La experiencia de la persona con secuelas de COVID-19 y la percepción del cuerpo según la perspectiva de Merleauponty

Audrey Moura Mota Gerônimo ORCID: https://orcid.org/0000-0003-0193-0253 Universidade Federal de Alagoas, Brasil E-mail: audreymmoura@gmail.com Isabel Comassetto ORCID: https://orcid.org/0000-0002-2389-9384 Universidade Federal de Alagoas, Brasil E-mail: isabelcomassetto@gmail.com

Amuzza Aylla Pereira dos Santos ORCID: https://orcid.org/0000-0001-6299-7190

Universidade Federal de Alagoas, Brasil E-mail: amuzza.pereira@eenf.ufal.br

Janaina Ferro Pereira

ORCID: https://orcid.org/0000-0003-4430-4156

Universidade Federal de Alagoas, Brasil E-mail: janaina.pereira@eenf.ufal.br

Jovânia Marques de Oliveira e Silva ORCID: https://orcid.org/0000-0001-7452-2651

Universidade Federal de Alagoas, Brasil E-mail: jovaniasilva@gmail.com

Elizabeth Moura Soares de Souza ORCID: https://orcid.org/0000-0002-5889-8197 Universidade Federal de Alagoas, Brasil E-mail: elizabeth@eenf.ufal.br

Raíssa Rafaella Santos Moreno da Silva ORCID: https://orcid.org/0000-0002-7265-9352 Universidade Federal de Alagoas, Brasil E-mail: raissarafaella13@gmail.com

Beatryz Rafaela Santos Lima

ORCID: https://orcid.org/0000-0003-3899-4728 Universidade Federal de Alagoas, Brasil E-mail: bearafaela@gmail.com

Pablo Mateus Medeiros Ferro

ORCID: https://orcid.org/0000-0002-1324-5598 Universidade Federal de Alagoas, Brasil E-mail: pablo.ferro@eenf.ufal.br

Nathalia Comassetto Paes

ORCID: https://orcid.org/0000-0003-0746-7810 Centro Universitário Tiradentes, Brasil

E-mail:nanacpaes@yahoo.com.br

Marcy Lins de Albuquerque Pinheiro Machado ORCID: https://orcid.org/0000-0001-9231-8750

Centro Universitário CESMAC, Brasil E-mail: marcy_pinheiro@hotmail.com

Kelly Juliana de Araújo Silva ORCID: https://orcid.org/0000-0002-7319-0621 Centro Universitário Faculdade Venda Nova do Imigrante, Brasil E-mail:kjaskjas25@hotmail.com

Lucas Hildebrando Sales Silva ORCID: https://orcid.org/0000-0002-8041-1867 Centro Universitário Tiradentes, Brasil E-mail: lucas.hildebrando@hotmail.com 


\begin{abstract}
Resumo
As sequelas da COVID-19 têm um impacto real na qualidade de vida das pessoas que entraram em contato com o vírus SARS-CoV-2, podendo persistir por tempo indeterminado. Objetivo: Desvelar a percepção do vivido pelas pessoas com sequelas da COVID-19. Métodos: Estudo qualitativo de abordagem fenomenológica segundo Merleau-Ponty, realizado com 14 pessoas diagnosticadas com sequelas da COVID-19 e que estavam em tratamento no período da realização das entrevistas fenomenológicas, no período de fevereiro a maio de 2021. A entrevista foi guiada pela questão disparadora: "Conte qual a percepção sobre o seu vivido com sequelas da COVID-19, como afetou sua mente e corpo". Resultados: Trata-se de um recorte da dissertação de Mestrado em Enfermagem intitulada "A percepção do vivido pelas pessoas com sequelas da COVID-19”, aprovada pelo CEP/UFAL, CAAE de n. 41216620.6.0000.5013. Os resultados evidenciaram quatro unidades ontológicas que foram analisadas e interpretadas à luz do referencial teórico-filosófico de Maurice Merleau-Ponty. Dentre as categorias que emergiram dos depoimentos, apresenta-se a unidade ontológica "Percebendo seu corpo doente e vivendo no mundo-da-COVID-19" (corpo). Conclusão: Pude perceber que o sersequelado pela COVID-19 possui um corpo com limitações que tem seu mundo alterado de forma abrupta, tendo suas formas de se relacionar através dos sentidos impactado (perda do olfato/paladar); composto por uma mente que já não recorda do dia que não teve medo, insegurança, temeu por sua vida e dos que ama. Espera-se que esse estudo possa contribuir na implementação de iniciativas que sejam capazes de ofertar uma assistência humanizada.
\end{abstract}

Palavras-chave: Enfermagem; Pesquisa qualitativa; Infecção pelo SARS-CoV-2; COVID-19.

\begin{abstract}
The sequelae of COVID-19 have a real impact on the quality of life of people who come into contact with the SARSCoV-2 virus, and may persist indefinitely. Objective: Unveil the perception of what is experienced by people with sequelae of COVID-19. Methods: Qualitative study with a phenomenological approach according to Merleau-Ponty, carried out with 14 people diagnosed with sequelae of COVID-19 and who were undergoing treatment during the period of the phenomenological interviews, from February to May 2021. The interview was guided by the triggering question: "Tell me what your perception of your lived with COVID-19 sequels is, how it affected your mind and body." Results: This is an excerpt from the Master's thesis in Nursing entitled "The perception of what is experienced by people with sequelae of COVID-19", approved by CEP/UFAL, CAAE no. 41216620.6.0000.5013. The results showed four ontological units that were analyzed and interpreted in the light of the theoretical-philosophical framework of Maurice Merleau-Ponty. Among the categories that emerged from the testimonies, the ontological unit "Perceiving your sick body and living in the world-of-COVID-19" (body) is presented. Conclusion: I could see that the being-sequenced by COVID-19 has a body with limitations that has its world abruptly changed, having its ways of relating through the senses impacted (loss of smell/taste); composed of a mind that no longer remembers the day that he was not afraid, insecure, feared for his life and those he loves. It is hoped that this study can contribute to the implementation of initiatives that are capable of offering humanized care.
\end{abstract}

Keywords: Nursing; Qualitative research; SARS-CoV-2 infection; COVID-19.

\title{
Resumen
}

Las secuelas de COVID-19 tienen un impacto real en la calidad de vida de las personas que entran en contacto con el virus SARS-CoV-2 y pueden persistir indefinidamente. Objetivo: Desvelar la percepción de lo vivido por personas con secuelas de COVID-19. Métodos: estudio cualitativo con abordaje fenomenológico según Merleau-Ponty, realizado con 14 personas diagnosticadas con secuelas de COVID-19 y que estaban en tratamiento durante el período de las entrevistas fenomenológicas, de febrero a mayo de 2021. La entrevista fue guiada por la pregunta desencadenante: "Dime cuál es tu percepción de lo que viviste con las secuelas del COVID-19, cómo afectó tu mente y tu cuerpo". Resultados: Este es un extracto de la Tesis de Maestría en Enfermería titulada "La percepción de lo vivido por personas con secuelas de COVID-19", aprobada por CEP / UFAL, CAAE no. 41216620.6.0000.5013. Los resultados mostraron cuatro unidades ontológicas que fueron analizadas e interpretadas a la luz del marco teórico-filosófico de Maurice Merleau-Ponty. Entre las categorías que surgieron de los testimonios, se presenta la unidad ontológica "Percibir tu cuerpo enfermo y vivir en el mundo-de-COVID-19" (cuerpo). Conclusión: pude ver que el ser secuenciado por COVID-19 tiene un cuerpo con limitaciones que tiene su mundo cambiado abruptamente, impactando sus formas de relacionarse a través de los sentidos (pérdida del olfato / gusto); compuesto por una mente que ya no recuerda el día en que no tuvo miedo, inseguro, temido por su vida y los que ama. Se espera que este estudio pueda contribuir a la implementación de iniciativas que sean capaces de ofrecer una atención humanizada.

Palabras clave: Enfermería; Investigación cualitativa; Infección por SARS-CoV-2; COVID-19.

\section{Introdução}

Trata-se de um estudo pautado na abordagem qualitativa do tipo fenomenológico no referencial teórico-filosóficometodológico de Merleau-Ponty, a qual buscou as percepções do vivido na pandemia pela pessoa sequelada pela COVID-19, sendo um recorte da dissertação de mestrado intitulada: “A percepção do vivido pelas pessoas com sequelas da COVID-19”, 
aprovada pelo CEP/UFAL, CAAE de $\mathrm{n}^{\circ}$. 41216620.6.0000.5013, com parecer $\mathrm{n}^{\circ}$. 4.506.421 de 21/01/2021. O interesse em estudar esta questão surgiu a partir do contexto atual de enfrentamento da pandemia pelo novo Coronavírus é resultante das inúmeras pessoas que vivenciaram o adoecimento pela COVID-19 e consequentemente evoluíram com sequelas mesmo após a cura da doença.

A pandemia chegou de forma inesperada, repercutindo não apenas no cenário médico e epidemiológico em escala global, mas também resultando em impactos sociais, políticos, econômicos, culturais e históricos. Mesmo sendo uma sociedade onde se vive em meio a diversos avanços tecnológicos, todos se viram frente à imposição do essencial isolamento social com o propósito de conter o avanço do vírus, reservando um distanciamento compelido para os seres que são caracteristicamente sociáveis.

Os números relacionados à COVID-19 são alarmantes, seja de infectados diagnosticados com o agravo mesmo considerando a subnotificação por não testagem da totalidade de sintomáticos, seja de pessoas que não resistiram e vieram a óbito, forçando a se reconhecer que se trata de uma situação que deve ser no mínimo analisada para além do aspecto numérico, devendo-se considerar a pandemia provocada pelo SARS-CoV-2 de acordo com suas particularidades que revelaram os impactos que extrapolam a infectologia e a epidemiologia (Souza, 2020).

Indubitavelmente se reconhece como determinantes relacionados com a COVID-19 a interação existente entre pobreza, raça/cor, gênero, desemprego, escolaridade. A falta de acesso a saneamento básico e água tratada, à educação e aos serviços de saúde, o uso de transporte público sujeito à aglomerações e o fato de residirem em moradias precárias e superlotadas revelam as dificuldades enfrentadas para que tornasse possível realizar o adequado isolamento social, além do desemprego ou de vínculos informais que fragilizava ainda mais essa condição. Revela-se então a vulnerabilidade enfrentada pelo trabalhador da periferia e das regiões mais pobres pela falta de trabalho formal e assalariado que lhe garanta segurança social e estabilidade econômica, fatores que afetaram sobremaneira o distanciamento social necessário relacionado ao enfrentamento da pandemia (Kerr, et al., 2020).

A respeito da COVID-19, pontua-se que esta é uma doença resultante do vírus SARS-CoV-2. A COVID-19 é a denominação atual do novo coronavírus surgido em Wuhan (China), em novembro de 2019. Por ser um vírus que apresenta como características relevantes acelerada disseminação, severidade e dificuldade de contenção resultou na declaração do estado pandêmico pela Organização Mundial de Saúde (OMS) três meses após o registro dos primeiros casos. Essa situação exigiu dos diversos países de todo o mundo direcionamento de medidas objetivando a contenção do surto e redução da letalidade (Brasil, 2020).

O Ministério da Saúde no Brasil já em janeiro de 2020, antes mesmo dessa declaração, ativou o Centro de Operações de Emergências em Saúde Pública para o SARS-CoV-2. Convergindo ao previsto no Plano Nacional de Resposta às Emergências em Saúde Pública, restou o desafio de promover a consolidação das informações oficiais e novas evidências técnico-científicas divulgadas para se estruturar os protocolos nacionais de combate à COVID-19. Como etapas essenciais, foram estruturadas medidas de notificação, registro, investigação, manejo e adoção de medidas preventivas para direcionar a conduta dos profissionais da saúde e órgãos governamentais envolvidos no controle dos casos e óbitos em território brasileiro. Ademais, foi construído um consenso de especialistas nacionais e internacionais que resultou na definição do Manejo Clínico da COVID-19 (Brasil, 2020).

Frente a esse cenário, conhecer a respeito da COVID-19, como se dá sua evolução e quais as consequências que provocam no organismo humano se apresenta como prioritário. Inquestionável é a imensa gama de inseguranças e obscuridades em torno do vírus e do agravo, o que exige esforços de todos os segmentos para suprir as lacunas existentes.

Diante do exposto o objeto proposto para este estudo é "a percepção do vivido pelas pessoas com sequelas da COVID19". Considerando os desafios enfrentados decorrentes desta pandemia, optou-se por este objeto de estudo devido à necessidade 
da realização de pesquisas que venham construir o conhecimento referente às sequelas decorrentes da COVID-19, a fim de dar subsídios para a assistência às pessoas que tiveram suas vidas alteradas após a infecção pelo SARS-CoV-2. Deste modo, a proposta deste estudo apresenta como questão norteadora: "Qual a percepção do vivido pelas pessoas com sequelas da COVID19 ?".

O presente estudo se justifica pela magnitude que a pandemia da COVID-19 alcançou, exigindo aprender a respeito do vírus e de como compromete o organismo humano, a fim de contribuir na estruturação de estratégias que possibilitem o concreto e eficiente enfrentamento para viabilizar que se supere o cenário atual.

Ademais, a importância desse estudo se encontra embasada nos diversos benefícios que se propõe a trazer, no que diz respeito à atenuação dos danos decorrentes do SARS-CoV-2, da pandemia e dos estressores a ela associada. Ressalta-se que por estarmos vivenciando uma situação singular frente ao cenário da nova pandemia, há demasiada preocupação com o enfrentamento das doenças respiratórias agudas e crônicas, pois, acabam se sobressaindo das demais e carecendo de uma compreensão significativa que envolve diferentes vivências por pessoas que tiveram tal consequência proveniente do adoecimento e terão que ter consigo tal sequela no seu cotidiano pós doença, com consequente impacto na qualidade de vida.

Dessa forma, este estudo pretende construir meios para que a assistência a esse grupo de indivíduos se dê de acordo com suas demandas e necessidades, visto se tratar de um agravo como já apontado desconhecido somado às particularidades do cenário que se está vivendo.

\section{Metodologia}

Tendo em vista a natureza do objeto, trata-se de um estudo pautado na abordagem qualitativa do tipo fenomenológico no referencial teórico-filosófico-metodológico de Merleau-Ponty, a qual buscou as percepções do vivido na pandemia pela pessoa sequelada pela COVID-19 (Merleau-Ponty, 2011). Haja vista a natureza do objeto de exploração, revelou-se a opção pela pesquisa qualitativa. A fenomenologia orienta o enfoque do estudo, a fim de compreender os fenômenos que o cercam e por possibilitar garantir o rigor no processo de desvelamento do fenômeno que mostra o mundo vivido pela pessoa.

Assim, a abordagem qualitativa permite ao pesquisador a aplicação prática do conceito de inseparabilidade, conduzindoo a um mundo repleto de situações novas que se apresentam de forma extraordinária e que remete a uma inusitada atitude de estar-no-mundo. Como consequência, amplia-se e se aprofunda o entendimento que se tem do mundo, resultando em uma nova definição da ação-no-mundo, em que a cosmovisão requer uma extrapolação da mera representação racional ou tentativa mental de se apreender a realidade, alcançando uma nova definição global da atitude até então apresentada. Logo, trata-se de uma mudança efetiva na conduta de estar-no-mundo, sendo uma atitude holocentrada na pessoa e na sua busca intrínseca de se restabelecer como Ser (Crema, 1995).

A busca em desvelar o vivido pela pessoa sequelada pela COVID-19 durante a pandemia do SARS-CoV-2 exigiria uma fundamentação teórico-filosófica que viabilizasse o processo de descoberta do Ser com sequelas decorrentes do adoecimento e suas percepções sobre a experiência vivida em Seu-corpo no pós COVID-19. Tal processo se tornaria ainda mais significativo ao explicitar o declínio de suas condições até então naturais cotidianamente, e que frente às sequelas passaram a apresentar limitações e restrições, entremeadas com os sintomas clínicos desconfortáveis que persistiam e não tinham perspectiva de superação.

Assim, a fenomenologia parte do esmiuçar rigoroso das experiências humanas enquanto ciência descritiva, carecendo da reflexão para viabilizar a observação das coisas tal qual como se manifestam, o que torna possível sua descrição. Trata-se do que está passível de ser descoberto de forma genuína por se apresentar de forma potencial, apesar de nem sempre estar visível partindo de caminhos próprios e adequados. Representa enfim, o encontro com as coisas mesmas e, assim sendo, exige a 
suspensão de qualquer julgamento acerca de sua existência, propriedades reais e mesmo características objetivas que aparecerem, carecendo que se abandone os pressupostos a elas relacionados, a chamada suspensão fenomenológica ou epoché.

Jean Jacques Maurice Merleau-Ponty, já em 1945, afirmou que a fenomenologia se resume em definir a essência de todas as coisas, seja da percepção ou da consciência. Como um dos mais fiéis ao pensamento husserliano, defende que se trata de uma filosofia que busca repor as essências na existência, partindo sempre da sua factibilidade. É transcendental já que caminha partindo tanto das afirmações da atitude natural na sua compreensão, quanto por envolver as questões anteriores à reflexão, ou seja, é o estar sempre "ali", tal qual uma presença inalienável do mundo "vivido". Assim, o desafio está centrado no reencontro ingênuo com o mundo, o primeiro olhar de descoberta, sendo a fenomenologia a representação um amplo movimento científico e espiritual, variado e ramificado que remete historicamente à Edmund Husserl (Merleau-Ponty, 2011).

O cenário do estudo foi o Centro de Especialidades Eliane Machado, inaugurado em 13 de agosto de 2020 e que foi criado para atender as pessoas com sequelas da COVID-19. Composto por um quadro multiprofissional constituído de médicos de diversas especialidades e enfermeiros qualificados, trata-se de uma das respostas da Secretaria Municipal de Saúde de Maceió no enfrentamento da pandemia do SARS-CoV-2. Ressalta-se que Maceió é um dos primeiros municípios a disponibilizar um serviço específico para tratar esse grupo de pessoas dentro da Rede SUS local (Diário do Poder, 2020; SECOM Maceió, 2020).

Como etapa inicial do estudo, foi realizada uma busca na base de dados Literatura Latino-Americana e do Caribe em Ciências da Saúde (LILACS) e Medical Literature Analysis and Retrieval Sistem on-line (Medline) com os termos "COVID19", "Doença por Coronavírus-19", "Infecções por SARS-CoV-2", "Infecções por Coronavírus", "Pós COVID-19”, no recorte temporal de 2019-2021.

Em seguida, utilizou-se a técnica de entrevista fenomenológica, conforme instrumento norteador criado, tendo sido guiadas por uma pergunta norteadora: "Conte qual a sua percepção sobre o seu vivido com sequelas da COVID-19, como afetou sua mente e corpo". Com o intuito de alcançar o máximo de fidedignidade na fase da análise, foi solicitado aos participantes a autorização prévia para utilizar um gravador de voz.

Foi utilizado como critério de inclusão: pessoas que tiveram diagnóstico de COVID-19 e com sequelas decorrentes do agravo; com idade superior a 18 anos e que estavam em acompanhamento pela equipe técnica do Centro de Especialidades Eliane Machado. Não foram incluídas no grupo de participantes deste estudo, pessoas que apresentavam qualquer divergência/confusão na fala, alteração na sua sensopercepção e/ou algum tipo de transtorno mental. A aceitação do convite para participar da pesquisa foi formalizada com a assinatura por parte dos participantes e da pesquisadora do Termo de Consentimento Livre e Esclarecido (TCLE), em duas vias, seguindo os critérios exigidos pelos normativos éticos vigentes.

Para a análise das descrições vivenciais, foi utilizada a técnica da Analítica da ambiguidade, uma metodologia de análise criada por Sena e colaboradores (2010), baseada na redução fenomenológica de Husserl e na ontologia da experiência de Merleau-Ponty. As descrições dos depoimentos colhidos nas entrevistas com as pessoas com sequelas da COVID-19, após serem transcritas na íntegra, foram submetidas à técnica da Analítica da Ambiguidade, que permitiu que o pesquisador alcance a percepção sob o ponto de vista de quem a vivencia e tem sido utilizada como estratégia adequada para a organização dos depoimentos do vivido em categorias empíricas, permitindo a compreensão dos fenômenos como se mostram à percepção.

$\mathrm{Na}$ última etapa, as unidades ontológicas contidas nos discursos foram agrupadas e relacionadas entre si, interligando os sentidos desvelados nos depoimentos, possibilitando a identificação de 04 (quatro) diferentes unidades ontológicas que desvelaram que a pessoa com sequelas da COVID-19 perceberam mudanças no seu corpo, vivenciando sentimentos de ambiguidade, conscientizando-se do mundo por meio do corpo no tempo e no espaço, refletindo sobre suas sequelas provenientes da COVID-19 e reconhecendo novas maneiras de coexistir no mundo. Aqui será apresentada a unidade ontológica 01: Percebendo seu corpo doente e vivendo no mundo-da-COVID-19 (corpo). Participaram desta pesquisa 14 (catorze) pessoas que 
passaram pela COVID-19 e desenvolveram sequelas decorrentes do agravo e que estão sendo acompanhadas no Centro de Especialidades Eliane Machado.

\section{Resultados e Discussão}

O processo de adoecimento na maioria das vezes leva o indivíduo a buscar forças para que encontre condições de superar um momento que pode ser gerador de grande apreensão e desconforto dada a sua condição clínica. No contexto da COVID-19 não é diferente, ainda mais por se estar inserido em uma pandemia em que se acumulam perdas e que provocou mudança inclusive no que tange ao enfrentamento do luto. O corpo pode passar a ser considerado um fardo decorrente da doença, apesar de representar o instrumento que revela a nossa presença no mundo, agindo como elo de ligação entre o interior (mente) e o exterior (mundo). Assim, concebendo o corpo como a abertura ao mundo da pessoa, sua presença inalienável (corpo) é revelada quando do enfrentamento da dor e da doença, que mesmo não sendo possível ser exteriorizada, a dor é vivida no seu interior, sendo refletida sua presença através do corpo, atraindo a atenção para tal processo (Renaud, 2010).

Desta feita, faz-se necessário reconhecer que o corpo não pode ser visto como uma redução do indivíduo. Assim, partindo dessa visão de corporeidade, de ser-no-mundo, a técnica de entrevista fenomenológica aplicada para que se realizasse a escuta atenciosa tornou possível o caminhar nas dimensões ôntica e ontológica, tendo a analítica de ambiguidade papel preponderante sob a ótica de Merleau-Ponty. Como resultado, alcançou-se a partir das dimensões relacionais presentes nos diferentes momentos do processo de escuta do vivido, que através da experiência perceptiva tornou possível o contato com a generalidade intercorporal. Os sentimentos, os temores e as incertezas trazem uma gama de significados quando avaliados no contexto da pandemia, do desconhecido que o SARS-CoV-2 nos trouxe e ainda provoca. A COVID-19 se apresenta de formas diferentes, apesar de trazer para o cotidiano a insegurança e o medo pelo futuro e por sua própria saúde.

As crenças religiosas, a forma como enfrenta o luto, as prioridades estabelecidas pelo outro, representando sua forma de Ser-no-mundo, não deve ser julgada, uma vez que não cabe críticas ou condenações. O que deve ser tratado como foco é de que forma as variáveis que conduzem o comportamento humano determinam seus atos, onde se torna possível interceder para que se promova qualidade de vida e recuperação da saúde. Desenvolver o olhar sensível capaz de reconhecer essas "variáveis" se revela como um caminho para se conseguir prestar uma assistência humanizada e holística. Por estar alicerçada na inseparabilidade da vida concreta e de sua história, a fenomenologia merleaupontyana explicita o fato do corpo representar o "veículo" do ser-no-mundo, que situa o sujeito temporal e espacialmente, como pode ser observado nas falas a seguir.

Iniciando o percurso em direção ao desvelar do fenômeno proposto, não havia outro caminho senão o de trazer o processo de adoecimento do corpo pela COVID-19 que é a representação do ponto gerador que resultou na condição essencial que integra o fenômeno oculto da pessoa sequelada. A forma como a pessoa passou a ver seu corpo doente e se defrontou vivendo no mundo-da-COVID-19 gerou uma gama de vividos que alteraram seu corpo. A partir de tal processo, pode-se identificar que inicialmente o vivido durante o estar-com-COVID-19 foi a representação de momentos de dor e sofrimento, tão inerente ao estar doente, mas também envolveu angústia, medo, desespero e sentimento de abandono. Vale ressaltar que é através do corpo que a pessoa se expressa em toda a sua existência.

Todavia, mesmo com a presença da negação à doença inicialmente, P4 ressalta a importância de seguir as orientações médicas para que possa se recuperar. Expressou também o temor pela família, especialmente frente às suas fragilidades, um ponto de vulnerabilidade para ela. Como resposta à necessidade de protegê-los, reforçou os cuidados individuais, adotando uma rotina que favorecesse o objetivo autoimposto.

O estar-com-COVID-19 para P3 vem acompanhado por sentimento de medo e insegurança, seja pela falta de conhecimento acumulado a respeito da doença, seja decorrente da falta de um tratamento padronizado instituído. Enquanto se 
está nesse dilema, o estado clínico vai ficando cada vez mais comprometido e o que se observa é a vivência de momentos de intensa agonia e desespero, antes nunca vivenciados. A família se vê impotente, enquanto o seu familiar querido piora expressivamente.

Já P5 identificou que mesmo com as orientações disponibilizadas nos veículos de comunicação, que permitiram a identificação de sintomas do agravo, a insegurança era uma constante, revelando o medo por seu bem-estar e de seus familiares; enquanto que para P13, o enfrentamento da doença e a manutenção de quadros desconhecidos anteriormente ao adoecimento revela o processo de compreensão da existência de sequelas da COVID-19. O impacto é imenso e, no que se refere ao desenvolvimento das atividades de vida diárias (AVDs), apresentando-se como algo que lhe provoca intensa angústia, levando o indivíduo a se reconhecer como alguém com limitação.

[...] Eu comecei com um resfriado, desse resfriado eu fiquei uns dias sem sentir cheiro e sem sentir o sabor da comida, mas ai eu pensei que era por conta do resfriado que eu tinha [...] e depois do resfriado eu fiquei boa do resfriado, só que permaneceu ainda [...] sem sentir cheiro, sem sentir sabor (P4).

[...] Eu tava me sentindo muito cansado, um cansaço muito forte, dores no corpo, dor de cabeça de uma maneira que eu nunca tinha sentindo antes. [...] (P5).

[...] O cansaço só piorando, a noite eu ficava com muita dificuldade para deitar. [...] Olha, outra coisa que eu percebi, assim, eи esqueço muito das coisas, eu tenho palavras simples que de repente dá um apagão. [...] Eu comecei a fazer o tratamento, meu cabelo caiu viu, bastante [...] Tinha o cabelo comprido, tive que cortar curtinho, a memória, o que me mais prejudicou foi a memória. Esqueci muito das coisas, quando eu ia falar palavras simples dava aquele apagão (P13).

[...] Meu problema na verdade é que isso me deu medo no início, se estava até sem saber como tratar [...]. E acabei ficando internado [...]. E aí eu tive muita ânsia de vômito, teve um dia, por exemplo, que eu fiquei ajoelhado no banheiro para vomitar, botei a cabeça dentro do banheiro, depois eu me deitei no chão, eu não sabia o que fazer. Minha esposa ficava desesperada, meus filhos desesperados, porque estava me sentindo tão mal que até falava assim "se o tratamento de quimioterapia desse esse enjoo todo, é uma tortura e eu nunca vou querer tomar", acredite, porque eu sofri muito [...] (P3).

O cansaço respiratório vivenciado por P13 foi de grande angústia no momento inicial, mas nada comparado aos lapsos de memórias que passaram a integrar seu cotidiano após a COVID-19. Assim, fica claro o defendido por Ponty, no que se refere à pessoa que passou pela experiência do estar-com-COVID-19, que precisou aprender e compreender cada fase na medida em que as vivencia. Para tanto, vai percebendo as novas relações frente às mudanças que vão ocorrendo em relação ao seu corpo, resultando em uma nova forma de interagir consigo próprio. Esta nova percepção (corporal, afetiva, mental ou social) é resultante desse processo de mudança e é perceptível nas falas, explicitando que é através do corpo que a pessoa com COVID-19 se vê no mundo, defrontando-se com suas próprias limitações e interagindo com os outros.

Nesse contexto, Ponty (1990) coloca que é o fenômeno que representa tudo aquilo que é percebido pela consciência para a fenomenologia, atribuindo um sentido no momento da percepção pela consciência, dando sentido ao fato. Assim, precedendo qualquer ato de categorização, a percepção é posterior ao fenômeno, sendo a ciência, a linguagem e a cultura uma expressão desta.

Comoli (2020) explicita que por ser nos pulmões geralmente o primeiro impacto percebido do SARS-CoV-2, a pessoa se sente tomada por intensa insegurança devido ao comprometimento da capacidade de conduzir sua vida com normalidade. Entretanto, são os danos provocados no SNC que são muito mais chocantes devido à sua capacidade de subjugação, uma vez que se apresentam com maior durabilidade, dada as características intrínsecas das células nervosas (difícil regeneração). Como repercussão, por ser o sistema responsável pela coordenação das funções orgânicas, tem-se as incapacidades que se apresentam tão limitantes. 
Também vale considerar que, nesse cenário de comprometimento imposto ao corpo pelo adoecimento, o cuidado de enfermagem se apresenta como algo que abrange toda a pessoa, não sendo algo exclusivamente objetivo. Como consequência, é exercido sobre o corpo uma resposta que se centra na complexidade do ser da pessoa doente. Mesmo incluindo a dimensão do saber que resulta na prestação de um cuidado técnico, apreensível e passível de ser reproduzido, trata-se de uma assistência que se funda no corpo doente ou carente de cuidados, que existe na vida interior e na sua abertura ao mundo (ser-no-mundo). Para tanto, o corpo está como o centro do processo de mediação entre o indivíduo adoentado e o profissional da enfermagem que vai prestar os cuidados, que adota uma dimensão específica e que se alicerça na atenção à interioridade do corpo adoentado (Renaud, 2010).

O processo de adoecimento no vivido por P12 esbarra no diagnóstico que nem sempre se dá em tempo oportuno. Uma das dificuldades da adequada assistência para os usuários com COVID-19 é o início do tratamento de modo a garantir que receba o que lhe for necessário. Percebe-se que mesmo frente a um diagnóstico negativo, o se sentir doente leva a uma confirmação diagnóstica condizente ao quadro que está apresentando, revelando que sua condição realmente exigia atenção. Situação similar vivenciou P2, já que o se "sentir doente" acabou se concretizando através da confirmação diagnóstica e que refletiu no autocuidado e nas inseguranças advindas do processo de adoecimento. Tal insegurança pode ser observada na ampliação voluntária do período de isolamento, tanto quanto na sua fala que reconhece que ainda não estava recuperada, que não se sentia bem.

Já para P1 o processo de adoecimento se apresentou como penoso, chegando a ser desesperador quando se vivencia situações de perda, de verdadeira luta pela vida, como a que ele passou. Percebe-se que na medida em que o indivíduo busca suporte em suas crenças, reconhecendo seus limites, defronta-se com o temor pela vida que se revela no medo. A COVID-19 conduziu as equipes de assistência à saúde a reverem parâmetros clínicos e de cuidados, a redimensionar a assistência frente à sobrecarga de trabalho, em uma luta sem fim pela humanização diante de tamanha batalha pela vida. Ademais, o indivíduo adoentado, ao perceber a realidade que está enfrentando passa a refletir sobre sua própria vida, como permanecer lutando sem que perca sua identidade, seu referencial de vida. Trata-se de uma experiência angustiante, que põe à prova seus valores, suas prioridades e estabelece um novo juízo de valor a respeito de tudo que o cerca e que lhe diz respeito.

No início, [...] a gente não se sente muito bem, né?! Eu estava com aquela moleza, achei que era uma gripe [...]. Só que no outro dia eu já não conseguia mais levantar da cama. [...] A gente foi no HGE para fazer um Rx do pulmão [...] o médico disse que já viu que tinha alguma coisa. Eu fiz aquele teste, o swab do nariz e aí foi que deu positivo, sendo que eu sentia moleza, eu sentia febre, sabe?! Só que eu comecei a sentir o cansaço dentro do HGE. Aí eles já me colocaram no oxigênio [...]. Aí ela falou (a médica) que ia entrar com a medicação, que se eu não reagisse, podia ocorrer a entubação, mas graças a Deus não precisou entubar. Não fui para UTI. [...] Eu fiquei no quarto, né?! quando da internação e assim, graças a Deus, eu respondi bem [...] (P12).

[...] Eu fiquei em casa, mas eu fiquei mais de 21 dias porque eu não me sentia legal. Só no $15^{\circ}$ dia é que passou tomografia porque as costas estavam doendo e deu vidro fosco, deu $20 \%$ vidro fosco. Aí ele passou (o médico receitou medicação). [...] Eu voltei lá, mesmo assim, né?! Dizem que com 14 dias o vírus vai, né?! Mas eu voltei lá de máscara e tudo, mas não está boa não [...] (P2).

[...] Já estava com vontade de pedir para me entubar, que eu estava me sentindo muito mal [...]. Aí uma senhora que está lá comigo, eles entubaram, [...] de manhã, quando foi prá o começo da tarde ela deu uma parada. Aí eles foram reanimá-la através daquele choque e eu só vendo tudo, né?! E eu já com vontade de pedir pra me entubar, já passou a vontade. Dando choque aqui e injeção, aí reanimaram ela. Passou-se, outra parada. Aí reanimaram de novo, mais adrenalina e mais choque. [...] Já botaram a traqueostomia nela, fizeram um buraco. Aí com mais um pedaço, outra parada, três. Quando foi na quarta, ela não resistiu, aí faleceu. Aí eu vendo aquilo, “Ave Maria!" O pior de tudo foi quando chegaram os carinha com as sacola [...], só botaram a cortina quando ela tava na terceira, foi quando elas (enfermeiras) notaram que eu tava assim, querendo me aperrear. Aí fiquei rezando por ela, pedindo [...]. Quando chegou os cara (técnicos para recolher o corpo) com aquelas bolsas, "Ela é pesada, tem que botar em duas!", vestiram com aquele sacão, e por último [...] botou um cadeadozinho [...]. Aí eu disse "Não vai pra casa não? a família não ver 
não?”. "Não, não pode não!” (responderam). Ai eu, “Ave Maria, o caba é dado como indigente e se não for o caba, o caba vai ser enterrado o outro sem ser ele”. [...] Ai eu não quis mais entubar. Eu fiquei aperreado, ansioso e com o negócio de 1 hora, eles vieram me dizer que iam me entubar. Ai disse, "Não quero, não quero!'”. Foi aquela confusão, de jeito nenhum. [...] A pessoa ver os outros morrendo assim do lado e não quer de jeito nenhum [...] (P1).

Com a hospitalização, P1 se vê diante do momento crítico de adoecimento, quando se depara com o instante crucial, a luta pela vida e o desfecho com a morte, levando-o a se apegar a sua fé, buscando forças nas suas crenças. O adoecimento não se limita ao período da infecção. O estado em que se encontra após esse período revela a intensa necessidade de cuidados continuamente, em que pequenos detalhes fazem toda a diferença, que integram a assistência e que comprometem e prolongam o processo de recuperação. Com a COVID-19 não é diferente, e em relação às pessoas que precisaram ser hospitalizadas, especialmente aquelas que foram entubadas.

Uma vez que as manifestações clínicas da COVID-19 são classificadas como multiformes, por envolver desde pessoas assintomáticas a casos moderados a críticos, faz-se necessário um acompanhamento sistemático a fim de promover um enfrentamento adequado no decorrer da pandemia. Casos assintomáticos são diagnosticados pela presença de resultado detectável de exames laboratoriais (presença de ácido nucléico viral) apesar da ausência de sintomas específicos (febre, alterações gastrointestinais e/ou respiratórios) e de anormalidades significativas em exames de imagem. Todavia, o que merece atenção especial é que mesmo sendo assintomáticos, já foram relatados casos de transmissão da doença através do contato pessoa a pessoa com esse grupo de pessoas. Ressalta-se o fato de estarem apresentando um quadro assintomático ou mesmo sintomas leves da COVID-19 acaba por comprometer o autocuidado instituído, uma vez que não procuram por atendimento médico, não recebendo diagnóstico e conduz à subestimação da carga do agravo (Lai, et al., 2020).

No decorrer da análise dos depoimentos da pessoa com COVID-19 se percebe o "sentir-se doente" atribuindo ao seu vivido uma gama de significados que expressam como se deu sua relação no enfrentamento imediato à doença, como pode ser visto nos depoimentos. O "acordar" representa um renascimento, contudo cheio de limitações e de dificuldades, já que a fragilidade é uma realidade e a retomada da consciência nem sempre é imediata. Trata-se de uma pessoa que carece de tempo para ir compreendendo tudo pelo qual passou e pelo qual irá passar ainda.

Os sentimentos que vão se avolumando frente ao estar-doente está presente no vivido de P7 que explicita que o aparecimento dos sintomas e a percepção do adoecimento torna evidente uma fragilidade que precisa ser enfrentada e que é permeada por temor e insegurança. Mesmo com medidas que sempre solucionavam o mal estar que se estava sentindo, a manutenção do quadro deixa claro o desafio que representava o estar-com-COVID-19. Assim como P7 falou, P6 também percebe o processo de adoecimento como sendo permeado de inseguranças e indefinições quando ocorre demora no diagnóstico. O aparecimento de sintomas e a evolução do quadro clínico acaba aprofundado essa insegurança devido ao isolamento que se faz necessário, com o intuito de garantir uma recuperação mais adequada e minimizar a disseminação do vírus com aqueles que convive e que por ventura venha a encontrar. Dessa forma, une-se ao desconhecido oriundo do adoecimento, a solidão decorrente do isolamento e o temor pela própria vida.

Em consonância com o já dito, perceber-se como o ser-com-COVID-19 gera uma experiência impregnada por medo, em que o corpo fala que não está bem e que está necessitado de cuidados e atenção, como será possível visualizar nas falas logo abaixo.

[...] Eu comecei a ter uns sintomas assim, estranho, a moleza muito grande, [...] tive muita dor de cabeça e não parava, não parava de jeito nenhum. Quando foi no outro dia, eu amanheci assim com a garganta arranhando. Uma moleza muito grande no corpo, muito grande, pra mim horrível, a moleza horrível. [...] eu pensei que estava gripada, eu não pensei que era COVID, né?! Só que aí, no outro dia, no domingo, eu comecei com uma dor nas costas, uma dor perfurando [...]. Comecei a achar estranho e essa dor não passava, eu tomava remédio e essa dor não passava. Aí 
quando foi na segunda, eu fui comer um alimento e não senti o gosto, ai "Eita meu Deus! eu acho que eu estou com COVID!" $[\ldots]($ P7).

[...] Com umas 2 semanas depois que comecei a trabalhar no consultório na rua comecei a apresentar muita dor de cabeça. Depois a dor de cabeça começou dor no corpo, aí depois eu comecei a ter dispneia, depois foi começando a ter dor no peito. Foi quando eu tive muita dor de cabeça e comecei a ter dor no corpo eu já me afastei [...] Fiz 3 testes rápidos, todos deram negativo, aí uns dias depois a dispneia não tinha passado, o pico só tinha piorado, aí eu fui na UPA fiz o Swab [...], fiz um Raio X que mostrou que eu estava com pneumonia infiltrativa nos pulmões, [...]. Só que o resultado do meu COVID, [...] só saiu um mês depois [...], então eu fiquei esse tempo todo na dúvida se eu tinha tido ou não ou se tinha sido uma pneumonia [...] e nesse período eu fiquei isolado, totalmente isolado [...] (P6).

Fica claro que o enfrentamento da atual pandemia do novo coronavírus está permeado de tensão decorrente da exclusão da vida afetiva, o sofrimento do outro é uma vivência intransferível e permeada por inseguranças. Cada um que defina através de seu próprio juízo de valor o que é mais ou menos importante, levando-os a agirem de acordo com essa preocupação e valoração. Todavia, observa-se o reflexo dessa crise afetiva ao se perceber a necessidade de repensar a priorização dada à existência. Urge uma mudança na forma de pensar, nas preocupações priorizadas se a intenção for salvar vidas, visto que o afetivo é uma das formas que o corpo se revela e se expõe aos outros, permitindo interações e superações de limitações, como Ponty bem apresenta. Essa reflexão se torna possível ao se analisar sob o prisma da fenomenologia, trazendo o vivido como centro da questão, colocando a experiência como objeto a ser analisado e viabilizando a percepção de formas para sair da crise que a humanidade está passando na busca do retorno à normalidade, a partir da identificação de novas formas de interagir consigo mesmo e com os outros, especialmente diante das medidas sanitárias de segurança instituídas que exigem afastamento social para prevenção da disseminação do SARS-CoV-2.

O desafio está ancorado no reconhecimento da vida encarnada como sendo uma experiência em que o vivido do outro é valorizado, partindo das suas singularidades e respeitando suas subjetividades. Somente assim se concretiza o acesso às variadas facetas dos fenômenos e ao próprio fenômeno, o que é viabilizado somente através do vivido enquanto corporeidade. Assim, trazer a fenomenologia para a ciência da Enfermagem no que se refere aos cuidados de pessoas com suspeita ou infectadas pelo SARS-CoV-2 é permitir um olhar ao vivido por elas, aproximando suas realidades ao cotidiano da vida desses profissionais do cuidar. Nesse sentido, é possível enumerar as várias ações que permitiram não apenas uma assistência de enfermagem humanizadas nas diversas instituições de saúde em todo o país e no mundo, em especial com a busca de alternativas que pudessem romper com o afastamento imposto no ambiente hospitalar de suas famílias através de videochamadas e do conforto ofertado nos cuidados diários.

P6 trás também à tona as inseguranças vivenciadas pelos profissionais da área da saúde no exercício de suas funções. Estudos já identificaram o risco de infecção pelo SARS-CoV-2 no ambiente hospitalar por parte dos profissionais de saúde e de pacientes hospitalizados. Outra questão que merece atenção está relacionada a presença de comorbidades, com ocorrência de casos mais graves, uma vez que em estudos realizados havia a presença de doenças de base em pelo menos $20 \%$ dos casos de COVID-19 (Lai, et al., 2020).

No que se refere aos cuidados exigidos pelos pacientes graves de COVID-19, Comoli (2020) ressalta os riscos decorrentes do processo de desmame da VM ou mesmo frente à resposta inflamatória exagerada, que podem resultar em tromboses, embolia, AVC isquêmico e mesmo ataques cardíacos são passíveis de ocorrer. Como consequência da migração de coágulos para os diversos sistemas, a ocorrência de processos embólicos acaba representando mais um risco para essas pessoas. Como se não bastassem os riscos que já está enfrentado, pode ocorrer de pequenos coágulos migrarem pelo sangue ocasionando a obstrução de vasos que vai inviabilizar que as células sejam oxigenadas.

Já no estudo de Ding e colaboradores (2020) detectaram que independente da gravidade da evolução da doença (com presença ou não de sintomas respiratórios), apresentaram em mesmos níveis manifestações neurológicas (dor nos nervos, 
sudorese excessiva, alterações do olfato e do paladar). No entanto nos casos leves ou assintomáticos, foram menos propensos a apresentarem resposta do sistema imunológico (5,4\% tiveram febre), bem como formigamento e dormência (22,8\%) e deficiência visual $(8,8 \%)$, o que indica dano mais frequente no autonômico do nervo.

As falas de P11 e de P14 revelam o quando o processo de adoecimento é muito particular para cada indivíduo, explicitando o quanto o SARS-CoV-2 pode interferir de forma singular de organismo para organismo. Pode evoluir de forma leve, como pode se apresentar de forma aguda, com uma evolução rápida e que submete o indivíduo a si. O "se perceber doente" vai sendo intensificado com o aparecimento dos sintomas e com a evolução da doença, que é implacável e devastadora.

[...] Do calafrio já veio a febre. [...] Você já vai ficando aquele desânimo, o corpo já querendo fracassar. [...] Chegou lá a médica passou o exame [...] e daí deu positivo. [...] Com dois dias a gente pegou a tomografia, então meu pulmão já tava $25 \%$ e aí eu já tava ficando bem debilitado, né?! A doença já avançando rápido. Foi quando a doutora me deixou e solicitou a ambulância para me transferir para o Hospital da Mulher [...]. Já cheguei [...] muito fraco! O corpo todo dolorido, sem fome, só aquela vontade de tá deitado e quando eu cheguei [...] já fui fazer outra tomografia, [...] dois dias depois já deu 75\% e foi quando eu fiquei lá internado [...]. A sensação, a doença é coisa terrível! É horrível, horrível! Uma sensação horrível! Você não tem força pra levantar o braço, pra comer, não tem força pra ir no banheiro, não tem força pra nada! É só um cansaço mesmo. E, assim, você fica naquela: "Meu Deus! Me tire daqui" e aquela ansiedade ruim, aquela coisa ruim [...] (P11).

[...] Domingo a tarde eu comecei a ficar pior e fui para a médica e pedi para ela passar uma outra tomografia para mim, porque eu não estava sentindo uma melhora com a medicação. [...] eu estava bem pior com as dores, [...], a febre não cedia. [...] Eu fui de novo fazer uma outra tomografia e para minha surpresa já deu comprometimento variável de 50 a 75\% dos pulmões. Aí a gente viu que o negócio estava muito sério e eu entrei em contato com a médica [...]. Quando eu sai de lá (do hospital) mal conseguia caminhar. Estava muito fraco, muito debilitado, e assim, cansava com qualquer peso, qualquer movimento físico [...] (P14).

Rothan e Byrareddyn (2020) observaram a presença de maior número de leucócitos, sintomas respiratórios anormais e presença de níveis aumentados de citocina pró-inflamatórias no plasma de pessoas com COVID-19 (responsáveis pela promoção da gravidade da doença), além de valores acima da faixa normal de PCR e de D-dímero, além de alta taxa de hemossedimentação. Como principais quadros clínicos associados à patogênese do SARS-CoV-2, tem-se a presença de pneumonia, atrelada à incidência de opacidades em vidro fosco identificados em exames de imagem e de lesão cardíaca aguda.

Reportando aos dados apresentado no estudo em tela, as participantes P8 e P13 fazem referência a sequelas que começaram a apresentar imediatamente superarem o período de isolamento domiciliar, tendo em vista que não precisaram ser hospitalizadas, mas condizem com os achados do estudo que está sendo desenvolvido, como pode ser observado nas falas abaixo.

[...] Já no sexto dia da doença, aí eu fiquei sem cheiro e sem gosto. Na verdade, o gosto eu só sentia que era salgado ou doce. Você podia me dar uma carne ou um peixe. Eu não ia saber diferenciá-los, só ia lhe dizer que era salgado. E o doce também, você podia me dar um brigadeiro ou um doce de goiaba, eu ia dizer que era doce. Mas eu não sabia distinguir [...] O paladar, graças a Deus que era o pior voltou ao normal [...] (P8).

[...] Já que eu sou professora, [...] a gente começou dar aula online, fiquei trabalhando em casa, sem precisar sair, no início, mas o meu esposo que trabalha viajando, certo dia chegou em casa com muita febre e a gente ficou até com medo de saber realmente o que ele tinha, né?! Mas com o exame deu positivo, ele teve muita febre, não precisou ser internado [...]. Todos os dias já que eu tava em casa, não saia, logo cedo abria a janela, ia fazer faxina e eu não estava conseguindo realizar minhas atividades rotineira [...], tava cansando, para falar também, eu tinha muita dificuldade para falar. Eu percebia que eu tentava, mas ficava com falta de ar. Muita falta de ar [...] (P13).

P13 apresenta uma das consequências do adoecimento frente às vulnerabilidades socioeconômicas ao revelar a fragilidade desse contexto tão desigual ao expor a faceta das classes sociais em que poucos podem se dar ao luxo de permanecerem isolados, enquanto a maioria da população que integra a classe trabalhadora precisa se expor ao vírus para poder sustentar suas famílias e garantir o mínimo de dignidade. 
Considerando-se que, nas diversas fases da vida, a pessoa com sequela da COVID-19 não é composta puramente de carne, o corpo destas pessoas possui dimensões palpáveis, características que permitem a descrição da sua superficialidade, torna-se possível perceber que existe uma espessura neste corpo e que por meio dela se pode chegar ao âmago das coisas, fazendonos mundo e fazendo-as carne. Assim, conduz ao entendimento de que o corpo é o único caminho que nos conduz às próprias coisas, uma vez que compreendemos que não somos seres simples, mas sim singulares, repletos de "reentrâncias" e dotados de profundidade que é inacessível a quem não queira percorrer suas "curvas" e coexistir com quem está-com-sequela-da-COVID19.

Além disso, Martins e Rios (2020) identificaram que para minimizar o impacto funcional decorrente das sequelas desenvolvidas no pós COVID-19 exigem resposta rápida no processo de reabilitação, proporcionando uma otimização no nível de capacitação e ampliando a participação. Nas evoluções moderadas a graves, as sequelas observadas foram alterações respiratórias, motoras e neurocognitivas, merecendo destaque o descondicionamento físico e o comprometimento da deglutição.

A pessoa ao se perceber limitada, tendo seu corpo atingido pela doença e impactado pelas mudanças a ela relacionadas, identifica que se faz urgente a promoção de um processo de adaptação e dispara uma busca pelo reequilíbrio da sua condição de normalidade. O "sentir-se-com-COVID-19" está despido e agora começa outra etapa que a doença provoca na pessoa que dela adoece: o pós infecção.

\section{Considerações Finais}

Diante de todo o exposto sobre as sequelas, algo surpreendente é que nem sempre é a pessoa assistida em estado grave que apresenta comprometimentos significativos no pós adoecimento. A grande maioria de relatos das pessoas assistidas envolvem aquelas que apresentaram a forma branda ou moderada da COVID-19, permanecendo após a recuperação da infecção com algum tipo persistente de sequela, conforme observa Peres (2020). A síndrome pós COVID (ou long covid, do inglês "COVID longa") representa um quadro clínico que é resultante da repercussão do agravo no organismo e que é composto por um conjunto de sintomas inespecíficos. Em sendo um algo recente, ainda não se sabe muito a seu respeito, mas o que fica claro é que não acomete apenas pessoas que desenvolveram a forma grave da COVID-19 e que chegaram a ser internadas em UTI por longo período.

É inegável que a pandemia decorrente do SARS-CoV-2 afeta a todos os seres em geral, havendo a necessidade de se reconhecer a vulnerabilidade que determinados grupos estão expostos, a fim de viabilizar um mínimo de estado de bem-estar social, uma vez que influencia na expectativa de vida e no modo como se morre. $\mathrm{O}$ acesso à saúde é uma seara de igual fragilidade, na medida em que não se levar em consideração o papel preponderante que o SUS representa para toda a população brasileira e a importância de lutar por sua manutenção.

Sendo assim, reforçou-se a importância do contínuo estímulo às práticas preventivas, individuais e coletivas, configurando-se como essenciais para a proteção da população de modo a diminuir a disseminação viral e o número de vítimas que infelizmente não resistem à luta travada contra esse patógeno ainda pouco conhecido. Assim, a primeira conclusão decorrente deste estudo é que a COVID-19 repercute a médio e longo prazo sobre a saúde humana, agindo de forma direta e indireta, gerando um inegável impacto socioeconômico, por comprometer a produtividade de trabalhadores ativos, bem como na sua independência e no desenvolvimento das AVDs. Dentre esses trabalhadores, merece destaque aqueles da área da saúde, que acabam sendo infectados no exercício de suas funções no enfrentamento ao vírus.

A crise política que é enfrentada nos vários níveis de poder, seja pelas decisões baseadas no negacionismo à doença e à sua letalidade, seja na falta de ações orquestradas no combate à pandemia exige medidas sistemática e voltadas à proteção à vida e ao reconhecimento da dor dos milhares e milhares de enlutados em todo o país. 
No decorrer do caminho trilhado na busca de desvelar o vivido das pessoas com sequelas da COVID-19, pude perceber que o ser-sequelado possui um corpo com limitações, frustrado com essa nova realidade, que não consegue andar, correr, limpar a casa, carregar sacolas, subir escadas, realizar tudo o que outrora era parte do cotidiano. Um corpo que tem seu mundo alterado de forma abrupta, tendo suas formas de se relacionar através dos sentidos impactado (a exemplo da perda do olfato e do paladar). Um corpo composto por uma mente que já não recorda do dia que não teve medo, insegurança, temeu por sua vida e dos que ama. Possui um corpo que não dorme, permanece insone, que teme não parar de sentir dor de cabeça ou o corpo ou nas mãos ou nas pernas ou simplesmente ao respirar.

Nesse cenário, como resposta direcionada ao reconhecimento da problemática de saúde pública que a COVID-19 vai gerar em pouco tempo futuro em relação aos milhares de brasileiros que terão no pós infecção a batalha por recuperar sua independência e dignidade fragilizadas pelo processo de adoecimento, os municípios precisam encontrar caminhos para dar resposta às demandas que já começaram a surgir. O que fica claro é a necessidade de que sejam respeitados critérios essenciais como a humanização do cuidado, o acesso a todos que dele necessite e o atendimento ao indivíduo de forma holística. Ademais, é fator inquestionável a necessidade que sejam intensificados esforços que visem a promoção da acumulação de conhecimentos a respeito do SARS-CoV-2, de como se desenvolve a COVID-19 no organismo humano e quais as consequências que o indivíduo e os profissionais da saúde terão que enfrentar.

Essa caminhada enfrentou desafios que até foram considerados intransponíveis uma vez que precisou combater os temores que a pandemia enraizou na vida das pessoas que foram ouvidas, exigindo adequações relacionadas desde ao como se realizaria as entrevistas, até o real significado do que representa o epoché, uma vez que foi preciso lidar com vividos resultantes de experiências densas e assustadoras, repletas de angústias e dores, por vezes desesperançadas e enfrentando a fragilidade em sua atual condição mais crua.

Que esse estudo possa contribuir na implementação de iniciativas como o Centro de Especialidades Eliane Machado, especialmente pelo serviço ter assumido uma importância marcante na vida dos usuários assistidos por seus profissionais e que o cuidado humanizado seja uma marca registrada na assistência à saúde prestada no município de Maceió. Impera o desafio de alcançar um cuidado multiprofissional, em que o foco seja a pessoa assistida e suas demandas. Muito ainda existe para aprender sobre o vírus e como a COVID-19 repercute de forma tão singular em cada organismo que se instala, mas se faz essencial que iniciativas como essa sejam incentivadas de modo a permitir que possamos promover seu enfrentamento adequado à realidade que tenhamos que superar.

Como próximo seguinte à finalização desse estudo enquanto dissertação de mestrado, realizar-se-á publicações com as demais unidades ontológicas identificadas no decorrer do desenvolvimento da mesma e discutidas à luz da fenomenologia segundo Merleau-Ponty.

\section{Referências}

Brasil, República Federativa do. (2020). Ministério da Saúde. Secretaria de Atenção Especializada à Saúde. Departamento de Atenção Hospitalar, Domiciliar e de Urgência. Protocolo de manejo clínico da COVID-19 na Atenção Especializada. Ministério da Saúde. 48 p.

Comoli, E. (2020). Sequelas em pacientes recuperados de COVID-19 podem persistir por longo período. UNICAMP, Campinas. Especial Lab-19. https://www.unicamp.br/unicamp/noticias/2020/07/24/sequelas-em-pacientes-recuperados-de-covid-19-podem-persistir-por-longo-periodo.

Crema, R. Saúde e plenitude: um caminho para o ser. (5a ed.), Summus, 1995. 272 p.

Diário do Poder. (2020). Prefeitura de Maceió inaugura centro para tratar pacientes com sequelas de COVID-19: Unidade é a quinta voltada para vítimas de COVID-19, mas a primeira para tratar complicações. Diário do Poder, 13 de agosto de 2020. https://diariodopoder.com.br/brasil-e-regioes/alagoas/prefeiturade-maceio-inaugura-centro-para-tratar-pacientes-com-sequelas-de-covid-19.

Ding, H., Yin, S., Cheng, Y., Cai, Y., Huang, W. \& Deng, W. (2020). Neurologic manifestations of nonhospitalized patients with COVID- in Wuhan, China. MedComm., 1(1), 253-56. https://onlinelibrary.wiley.com/doi/epdf/10.1002/mco2.13. 
Research, Society and Development, v. 11, n. 1, e24611124874, 2022

(CC BY 4.0) | ISSN 2525-3409 | DOI: http://dx.doi.org/10.33448/rsd-v11i1.24874

Kerr, L., Kendall, C., Silva, A. A. M., Aquino, E. M. L., Pescarini, J. M., Almeida, R. L. F., Ichihara, M. Y., Oliveira, J. F., Araújo, T. V. B., Santos, C. T., Jorge, D. C. P. \& Filho, D. B. M. (2020). COVID-19 no Nordeste brasileiro: sucessos e limitações nas respostas dos governos dos estados. Ciência \& Saúde Coletiva, Ceará, 25(supl 2), 4099-120.

Lai, C.-C., Liu, Y. H., Wang, C.-Y., Wang, Y.-H., Hsueh, S.-C., Yen, M.-Y., Ko, W.-C. \& Hsueh, P.-R. (2020). Asymptomatic carrier state, acute respiratory disease, and pneumonia due to severe acute respiratory syndrome coronavirus 2 (SARS-CoV-2): Facts and myths. Journal of Microbiology, Immunology and Infection., 53(3), 404-12.

Martins, C. L. \& Rios, J. (2020). Os Desafios da Medicina Física e de Reabilitação em Portugal Durante a Pandemia por COVID-19. Cartas ao Editor, Acta Med Port., 33(7-8), 528-35.

Merleau-Ponty, M. (2011). Fenomenologia da percepção. (4a ed.), Editora: WWF Martins Fontes. 662 p.

Merleau-Ponty, M. (1990) O Primado da percepção e suas consequências filosóficas. Ed. Papirus. 93p.

Peres, A. C. (2020). Dias que nunca terminam: sintomas persistentes relacionados à Síndrome Pós-Covid surpreendem pacientes e pesquisadores. RADIS: Comunicação e Saúde, 218(1), 26-31.

Renaud, I. C. R. (2010). O Cuidado em Enfermagem. Pensar Enfermagem., 14(1), 02-08.

Rothan, H. A. \& Byrareddy, S. N. (2020). The epidemiology and pathogenesis of coronavirus disease (COVID-19) outbreak. Journal of Autoimmunity., 109(102433), 4p. https://www.sciencedirect.com/science/article/pii/S0896841120300469?via\%3Dihub.

SECOM Maceió. (2020). Maceió conta com centro para tratamento de sequelas da COVID-19. SECOM Maceió, 14 de agosto de 2020. http://www.maceio.al.gov.br/2020/08/rui-palmeira-inaugura-centro-para-tratamento-de-pacientes-com-sequelas-de-covid-19/.

Sena, E. L. S., Gonçalves, L. H. T., Müller Granzotto, M. J., Carvalho P. A. L. \& Reis, H. F. T. (2010). Analítica da ambiguidade: estratégia metódica para a pesquisa fenomenológica em saúde. Rev Gaúcha Enferm., 31(4), 769-75. https://doi.org/10.1590/S1983-1447201000040022.

Souza, D. O. (2020). A pandemia de COVID-19 para além das Ciências da Saúde: reflexões sobre sua determinação social. Ciência \& Saúde Coletiva, Alagoas, 25(1), 2469-77. 